\title{
Saberes e práticas sobre o corpo em movimento na Educação Infantil: perspectiva de professoras
}

\author{
Knowledge and practices about the body in motion in Childhood \\ Education: perspective of teachers
}

\section{Conocimientos $y$ prácticas sobre el cuerpo en movimiento en la Educación Infantil: perspectiva del profesor}

Dalila Maite Rosa Sena ${ }^{1}$; João Guilherme Rodrigues Mendonça²; Cláudia Regina Mota dos Santos ${ }^{3}$

\section{RESUMO}

Este trabalho tem por objetivo promover uma discussão e reflexão sobre o papel do corpo e movimento com e para as crianças da Educação Infantil e a sua importância para o desenvolvimento do pensamento reflexivo e autônomo das crianças, bem como identificar o conhecimento das professoras de um Centro de Educação Infantil do Município de Ji-Paraná/RO, sobre o "Corpo, Gestos e Movimentos" analisando as estratégias utilizadas para a realização das atividades. Para coleta dos dados utilizamos uma abordagem qualitativa. A pesquisa foi desenvolvida com sete professoras de um Centro Municipal de Educação Infantil da rede municipal de Ji-Paraná/RO. Realizou-se a análise dos dados partindo da articulação das informações obtidas com o referencial teórico que discutem a importância do movimento na Educação Infantil, Freire (1989, 2006), Garanhani (2008), Baecker (1996), Miranda (2008), entre outros. Como resultado, afirmamos que o movimento é de suma importância para o desenvolvimento integral da criança e deve ser considerado como parte essencial do planejamento do/a professor/a, uma vez que ele possibilita a aprendizagem em outras áreas do conhecimento.

Palavras-chave: Corpo e movimento; Educação Infantil; Saberes e práticas.

\begin{abstract}
This work aims to promote a discussion and reflection on the role of the body and movement with and for children in Early Childhood Education and its importance for the development of reflective and autonomous thinking of children, as well as identifying the knowledge of teachers in a Center of Child Education in the Municipality of Ji-Paraná / RO, on "Body, Gestures and Movements" analyzing the strategies used to carry out the activities. For the production of the data we use a qualitative approach. The research was developed with seven teachers from a Municipal Center for Early Childhood Education in the municipal network of Ji-Paraná / RO. Data collection was performed using a semi-open questionnaire and participant observation. Data analysis was carried out based on the articulation of the information obtained with the theoretical framework that discuss the importance of the movement in Early Childhood Education, Freire (1989, 2006), Garanhani (2008), Baecker (1996), Miranda (2008), among others. As a result, we affirm that the movement is of paramount importance for the integral development of the child and should be considered as an essential part of the teacher's planning, since it enables learning in other areas of knowledge.
\end{abstract}

Keywords: Body and movement; Child education; Knowledge and practices.

\footnotetext{
${ }^{1}$ Mestranda do Programa de Pós-Graduação Profissional em Educação Escolar (PPGEE/Prof) da Universidade Federal de Rondônia (UNIR), Porto Velho/RO - Brasil. E-mail: dalila_maite@hotmail.com

2 Doutor em Educação Escolar e docente do Programa de Pós-Graduação Profissional em Educação Escolar (PPGEE/Prof) da Universidade Federal de Rondônia (UNIR), Porto Velho/RO - Brasil. E-mail: jgrmendonca@unir.br

${ }^{3}$ Mestranda do Programa de Pós-Graduação Profissional em Educação Escolar (PPGEE/Prof) da Universidade Federal de Rondônia (UNIR), Porto Velho/RO - Brasil. E-mail: profclaudia33@gmail.com
} 


\section{RESUMEN}

Este trabajo tiene como objetivo promover una discusión y reflexión sobre el papel del cuerpo y el movimiento con y para los niños en la Educación Infantil y su importancia para el desarrollo del pensamiento reflexivo y autónomo de los niños, así como identificar los conocimientos de los docentes en un Centro de Educación Infantil en el Municipio de Ji-Paraná / RO, sobre "Cuerpo, Gestos y Movimientos" analizando las estrategias utilizadas para la realización de las actividades. Para la producción de los datos utilizamos un enfoque cualitativo. La investigación se realizó con siete docentes de un Centro Municipal de Educación Infantil de la red municipal de Ji-Paraná / RO. La recolección de datos se realizó mediante un cuestionario semiabierto y observación participante. El análisis de datos se realizó a partir de la articulación de la información obtenida con el marco teórico que discute la importancia del movimiento en Educación Infantil, Freire (1989, 2006), Garanhani (2008), Baecker (1996), Miranda (2008), entre otros. En consecuencia, afirmamos que el movimiento es de suma importancia para el desarrollo integral del niño y debe ser considerado como parte esencial de la planificación del docente, ya que posibilita el aprendizaje en otras áreas del conocimiento.

Palabras clave: Cuerpo y movimiento; Educación Infantil; Conocimientos y prácticas.

\section{INTRODUÇÃO}

Este estudo visa compreender a relação corpo e movimento na Educação Infantil, bem como destacar sua importância para o desenvolvimento motor da criança. A pesquisa desenvolvida é de caráter qualitativo e tem como objeto os saberes e práticas de professoras sobre o movimento com crianças de 04 e 05 anos de idade.

O espaço educacional deve ser um ambiente que favoreça o desenvolvimento pleno das crianças, considerando suas especificidades. Para garantir esse ambiente, as instituições de ensino são norteadas pela Lei no 9.394, que estabelece as Diretrizes e Bases da Educação Nacional (LDB) e as Diretrizes Curriculares Nacionais para a Educação Infantil (DCNEI) elaborado pelo MEC a partir da Lei 12.796/13 que visam a melhoria do ensino e possibilitam reflexões sobre a práxis pedagógica. 0 corpo em movimento faz parte desses documentos oficiais e precisa ser pensado enquanto prática na Educação Infantil.

De acordo com Silva (2011, p.33)

O corpo, ao constituir-se como uma linguagem, nos permite fazer parte do mundo, com ele construindo sentidos e estabelecendo processos comunicativos. Dessa forma, pensar o corpo na educação significa evidenciar o desafio de nos percebermos como seres corporais, resgatando o ser humano em sua complexidade (totalidade).

A aprendizagem na primeira infância é fundamentalmente lúdica, as crianças aprendem por meio de brincadeiras, é ainda no brincar que elas iniciam o processo de socialização. Contudo, esse trabalho deve ser conduzido com seriedade, pois o corpo em movimento na Educação Infantil engloba fatores afetivos, sociais, intelectuais e motores. Entretanto, alguns professores apresentam dificuldades em reconhecer a relevância do movimento no cotidiano das crianças e continuam enraizados em uma prática educativa tradicional, em que só é possível a aprendizagem se o corpo estiver imóvel e em silêncio.

De acordo com Richter (2006, p.32), "vivemos as marcas de uma educação que tolhe o movimento, a expressão corporal, como se este atrapalhasse o desenvolvimento da criança". Existe ainda uma separação entre a mente e o corpo e, apesar de essa teoria ter sido refutada por estudiosos, infelizmente, ela ainda está presente no contexto de muitas escolas. 
O Referencial Curricular para Educação Infantil traz construções importantes a respeito do movimento nesta etapa de ensino,

Ao lado das situações planejadas especialmente para trabalhar o movimento em suas várias dimensões, a instituição reflita sobre o espaço dado ao movimento em todos os momentos da rotina diária, incorporando os diferentes significados que Ihe são atribuídos pelos familiares e pela comunidade. Nesse sentido, é importante que o trabalho incorpore a expressividade e a mobilidade próprias às crianças (RCNEI, 1998, p.19, grifos nossos).

Assim, é preciso que os professores voltem suas práticas para o desenvolvimento da consciência corporal de cada criança, sendo capazes de refletir sobre a complexidade que envolve 0 descobrimento do corpo na Educação Infantil. Para tanto, faz-se necessário uma intencionalidade que considere os conhecimentos prévios das crianças e suas vivências, a fim de estimulá-las ao conhecimento do próprio corpo e todas as áreas de aprendizagem e desenvolvimento das crianças. (ARRIBAS, 2004).

\section{EDUCAÇÃO INFANTIL: ASPECTOS DA LEGISLAÇÃO E DOS DOCUMENTOS OFICIAIS}

Segundo o Referencial Curricular Nacional para a Educação Infantil - RCNEI (BRASIL, 1998), a Educação Infantil cresceu muito nos últimos anos, acompanhando as mudanças que ocorreram no mercado de trabalho e urbanização e com isso a sociedade passou a priorizar a infância e as suas experiências o que possibilitou o crescimento das instituições que atendem a esse público; tornou-se objeto de discussões realizadas por professores e demais profissionais interessados nessa etapa de ensino e no desenvolvimento da criança, fator que contribui para que a mesma fosse vista com mais atenção pelos governantes. Nesse sentido, o RCNEI de acordo com Brasil $(1998$, p. 13) se manifesta dizendo:

A conjunção desses fatores ensejou um movimento da sociedade civil e de órgãos governamentais para que 0 atendimento às crianças de zero a seis anos fosse reconhecido na Constituição Federal de 1988. A partir de então, a educação infantil em creches e pré-escolas passou a ser, ao menos do ponto de vista legal, um dever do Estado e um direito da criança (artigo 208, inciso IV). O Estatuto da Criança e do Adolescente, de 1990, destaca também o direito da criança a este atendimento.

Podemos observar a partir do RCNEI que a Educação Infantil passou a assumir a função de cuidar e educar, após debates a nível nacional e internacional, elevada ao patamar de mesma importância dos outros níveis de ensino, que tem como prioridade a qualidade da educação de crianças pequenas.

[...] essa qualidade advém de concepções de desenvolvimento que consideram as crianças nos seus contextos sociais, ambientais, culturais e, mais concretamente, nas interações e práticas sociais que Ihes fornecem elementos relacionados às mais diversas linguagens e ao contato com os mais variados conhecimentos para a construção de uma identidade autônoma. (BRASIL, 1998, p. 23).

O Artigo $4^{\circ}$ das Diretrizes Curriculares Nacionais da Educação Infantil (DCNEI, Resolução CNE/CEB no 5/2009) definem criança como

sujeito histórico e de direitos, que, nas interações, relações e práticas cotidianas que vivencia, constrói sua identidade pessoal e coletiva, brinca, imagina, fantasia, deseja, aprende, observa, experimenta, narra, questiona e constrói sentidos sobre a natureza e a sociedade, produzindo cultura (BRASIL, 2009, p. 18). 
O DCNEI traz, ainda, em seu Artigo 90, que os eixos estruturantes das práticas pedagógicas na Educação Infantil são as interações e a brincadeira, experiências estas que possibilitam as crianças estabelecer e apropriar-se de conhecimentos através de suas ações e interações com outras crianças, com adultos, o que permite não só aprendizagens, mas também o seu desenvolvimento e socialização.

A Base Nacional Comum Curricular (BNCC) foi fundamentada na DCNEI e traz seis direitos de aprendizagem e desenvolvimento na Educação Infantil, a saber:

- Conviver com outras crianças e adultos, em pequenos e grandes grupos, utilizando diferentes linguagens, ampliando o conhecimento de si e do outro, o respeito em relação à cultura e às diferenças entre as pessoas.

- Brincar cotidianamente de diversas formas, em diferentes espaços e tempos, com diferentes parceiros (crianças e adultos), ampliando e diversificando seu acesso a produções culturais, seus conhecimentos, sua imaginação, sua criatividade, suas experiências emocionais, corporais, sensoriais, expressivas, cognitivas, sociais e relacionais.

- Participar ativamente, com adultos e outras crianças, tanto do planejamento da gestão da escola e das atividades propostas pelo educador quanto da realização das atividades da vida cotidiana, tais como a escolha das brincadeiras, dos materiais e dos ambientes, desenvolvendo diferentes linguagens e elaborando conhecimentos, decidindo e se posicionando.

- Explorar movimentos, gestos, sons, formas, texturas, cores, palavras, emoções, transformações, relacionamentos, histórias, objetos, elementos da natureza, na escola e fora dela, ampliando seus saberes sobre a cultura, em suas diversas modalidades: as artes, a escrita, a ciência e a tecnologia.

- Expressar, como sujeito dialógico, criativo e sensível, suas necessidades, emoções, sentimentos, dúvidas, hipóteses, descobertas, opiniões, questionamentos, por meio de diferentes linguagens.

- Conhecer-se e construir sua identidade pessoal, social e cultural, constituindo uma imagem positiva de si e de seus grupos de pertencimento, nas diversas experiências de cuidados, interações, brincadeiras e linguagens vivenciadas na instituição escolar e em seu contexto familiar e comunitário. (BRASIL, 2017, p. 38).

Os direitos de aprendizagem e desenvolvimento que a BNCC preconiza para as crianças dessa etapa de ensino têm como objetivo assegurar condições para que elas aprendam a partir de situações desafiadoras e possam sentirem-se instigadas a resolvê-las, construindo "significados sobre si, os outros e o mundo social e natural". (BRASIL, 2017, p. 37).

Como vimos nos documentos oficiais, embora tenha passado por mudanças, muitas vezes, nas práticas pedagógicas, a Educação Infantil é compreendida como uma etapa para preparar a criança para o Ensino Fundamental. Desta forma, algumas práticas que deveriam ser desenvolvidas nessa etapa são deixadas de lado para dar ênfase a conteúdos que serão preparatórios para a alfabetização e com isso o movimento e a expressividade deixam de ser aspectos primordiais na Educação Infantil. (CLARA E FINCK, 2012).

Garanhani (2008, p. 128) destaca a importância de práticas pedagógicas que envolvam de forma total o desenvolvimento infantil: 
A escola da pequena infância, ao proporcionar um meio favorável ao desenvolvimento infantil nos seus diversos domínios - a afetividade, a cognição e o movimento, realiza a mediação entre a criança e o conhecimento culturalmente construído e traduzido em diferentes linguagens: oral, corporal, musical, gráfico-pictórica e plástica. Ao mesmo tempo, desenvolve na criança habilidades para a expressão e comunicação.

Torna-se necessário trabalhar a criança de forma integral, levando em consideração todas as suas potencialidades, sem dar ênfase em um campo de experiência e deixar o outro em defasagem. A prática pedagógica deve privilegiar o desenvolvimento nas diferentes linguagens, de forma que contemple a interação e comunicação da criança com o mundo. (GARANHANI, 2008).

De acordo com o Referencial Curricular Nacional para Educação Infantil - (RCNEI) as crianças se comunicam com o mundo por meio de seus movimentos e suas expressões corporais e faciais, que passam a ser uma ferramenta para interação com o ambiente que elas estão inseridas. Por isso a necessidade de trabalhar com o corpo já que é a partir da descoberta dele que a criança pode dar significados a suas expressões e, assim, ser possível integrar corpo e mente. (BRASIL, 1998).

As atividades de movimentos que as crianças realizavam diariamente há alguns anos eram consideradas suficientes para que as habilidades motoras fossem desenvolvidas e elas tivessem uma base para a aprendizagem motora, pois havia uma disposição de espaços amplos para brincar e explorar. (MIRANDA, 2008). Com o avanço das tecnologias, o estilo de vida das famílias mudou, principalmente das crianças, e tornou-se uma grande preocupação, pois parte do tempo livre delas é utilizado em frente à televisão, tabletes, celulares ou outros meios eletrônicos.

Nesse cenário atual, a escola possui a responsabilidade de propor atividades que superem essa defasagem no campo de movimentos e sedentarismo. Temos crianças que sabem utilizar celular com facilidade, mas não conseguem amarrar o cadarço do tênis ou manter o controle corporal durante uma corrida.

Desta forma a escola deve estar atenta às constantes transformações no cotidiano de forma crítica e reflexiva, a fim de acompanhar a evolução dos tempos e os desafios que a sociedade lhe impõe, bem como considerar a educação psicomotora das crianças e realizar um trabalho que contemple o corpo em movimento como precursor da aprendizagem.

\section{CAMINHO METODOLÓGICO}

O presente estudo foi realizado em um Centro Municipal de Educação Infantil da cidade de Ji-Paraná - RO, uma instituição de médio porte, com capacidade de 320 crianças pertencentes a diferentes classes socioeconômicas.

Considerando-se que "o conhecimento não é algo acabado, mas uma construção que se faz e refaz constantemente" (LÜDKE e ANDRÉ, 1986, p. 18), esta pesquisa teve como foco os saberes e práticas sobre o movimento do corpo na Educação Infantil. Utilizamos nesse estudo uma abordagem qualitativa exploratória, pois, como colocam Lüdke e André (1986, p. 11),

A pesquisa qualitativa tem o ambiente natural como sua fonte direta de dados, 0 pesquisador é o seu principal instrumento e o significado que as pessoas dão às coisas e à sua vida serão focos de atenção especial dado pelo pesquisador. 
O que possibilita "uma abordagem mais aprofundada da realidade dos sujeitos e uma melhor compreensão dos significados que eles dão para essa realidade e sua ação" (FIORENTIN, 2006, p. 85). Este estudo baseou-se em uma pesquisa de campo com observação participante. De acordo com Vergara, (2009, p.43), o estudo de campo é uma "investigação empírica realizada no local onde ocorre ou ocorreu um fenômeno ou que dispõe de elementos para explicá-lo. Pode incluir entrevistas, aplicação de questionários, testes e observação participante ou não", o que, para este trabalho, esse tipo de pesquisa favoreceu a análise dos dados. Segundo Gonsalves (2001, p.67),

A pesquisa de campo é o tipo de pesquisa que pretende buscar a informação diretamente com a população pesquisada. Ela exige do pesquisador um encontro mais direto. Nesse caso, o pesquisador precisa ir ao espaço onde o fenômeno ocorre, ou ocorreu e reunir um conjunto de informações a serem documentadas [...].

Após a assinatura do Termo de Consentimento Livre Esclarecido - (TCLE) a coleta dos dados ocorreu por meio de observações das aulas nos espaços externos, a fim de obter uma maior aproximação com as professoras e também analisar como o corpo e movimento são contemplados na prática pedagógica. Também realizamos um questionário com as professoras a fim de constatar as estratégias utilizadas para o desenvolvimento das aulas de movimento, bem como identificar as concepções e saberes a respeito do tema. $O$ instrumento de coleta de dados questionário, segundo Gil (1999, p.128), pode ser definido "como a técnica de investigação composta por um número mais ou menos elevado de questões apresentadas por escrito às pessoas, tendo por objetivo o conhecimento de opiniões, crenças, sentimentos, interesses, expectativas, situações vivenciadas etc.". Desta forma corresponde a um excelente instrumento de coleta de dados.

Os dados foram analisados e categorizados utilizando a técnica de análise de conteúdo (BARDIN, 1977). A autora oferece a possibilidade de analisar diferentes instrumentos tais como (observação, questionário e entrevistas), utilizando uma ordem cronológica de pré-análise, exploração do material e interpretação, possibilitada por esse método, oportunizando uma compreensão da realidade pesquisada.

\subsection{Análise dos dados:}

Após a coleta de dados, por meio de questionário, com dez (10) perguntas, sendo cinco (05) objetivas e cinco (05) subjetivas e observações, buscou-se analisar e interpretar as informações por meio de análise de conteúdo que conforme Bardin (1977, p.42) é:

Um conjunto de técnicas de análise das comunicações visando obter, por procedimentos, sistemáticos e objetivos de descrição do conteúdo das mensagens, indicadores (quantitativos ou não) que permitam a inferência de conhecimentos relativos às condições de produção/recepção (variáveis inferidas) destas mensagens.

Os dados foram trabalhados de forma qualitativa, tendo em vista a compreensão das informações coletadas e foram adotados os seguintes passos: primeiro realizamos a transcrição do questionário semiaberto, o conteúdo foi lido em sua totalidade, sem desconsiderar as informações relatadas. $\mathrm{Na}$ sequência fizemos uma releitura com a finalidade de estabelecer relações entre os subsídios teóricos e as respostas das participantes.

Como segundo passo, realizamos a codificação dos dados brutos criando categorias para maior compreensão e aproximação dos conceitos encontrados e condensação das informações pertinentes, o que possibilitou uma exposição dos conteúdos dos questionários e gerou um cruzamento dos dados obtidos e sua interpretação. 
Os dados foram construídos com base em três categorias: a) Concepção de movimento na Educação Infantil, b) $\mathrm{O}$ movimento e a aprendizagem e c) $\mathrm{O}$ espaço físico e o seu uso. A pesquisa foi realiza com sete professoras de um centro municipal de Educação Infantil da cidade de Ji-Paraná. Reiteramos que as falas apresentam apenas uma numeração como referência com a intenção de resguardar a identidade das professoras que fizeram parte da pesquisa.

Todas as professoras que participaram da pesquisa são licenciadas em Pedagogia e possuem pósgraduação em alguma área de conhecimento. De acordo com os dados coletados, as falas das professoras apontaram que as atividades de movimentos fazem parte do planejamento e são realizadas em média três vezes por semana, destacando como principais atividades: construção de torres, circuitos, rodas cantadas, jogar bola, pular corda, pega-pega, morto vivo e toca do coelho.

\section{a) Concepção de movimento na Educação Infantil}

No que se refere à importância do movimento para aprendizagem de crianças pequenas, todas as professoras concordaram que o campo de experiência movimentos é muito importante para o desenvolvimento da criança. A respeito disso, a Professora 05 afirmou que " $O$ movimento desenvolve a capacidade de criar, imaginar e se expressar por meio de gestos e movimentos".

A Professora 03 pontuou que "Com atividades de movimento a criança desenvolve melhor seu equilíbrio, orientação espacial, controle e conhecimento corporal." Percebemos na fala a professora que a mesma concorda que o movimento contribui para que as crianças se tornem conscientes de sua corporeidade e são essas experiências corporais que permitem a elas conhecerem os seus limites, suas potencialidades.

O autor Baecker (1996) afirma que a experiência no campo de movimentos, possibilita que a criança aprenda conceitos e ações, bem como ampliar sua independência, consciência própria, amadurecimento cognitivo e estimula a curiosidade, percepção e fomenta a curiosidade, para atribuir sentidos ao mundo.

"A criança aprende brincando, e o movimento ajuda a desestressar também" - afirmou a Professora 06. Vale a pena destacar que as atividades de movimentos devem explorar o brincar como forma de prazer, descontração uma vez que não há a necessidade de focar o brincar somente como aprendizagem formal. O autor Chateau (1987) afirma que "uma criança que não sabe brincar, uma miniatura de velho, será um adulto que não saberá pensar". (p. 14). Compreendemos, desta forma, que as atividades de movimentos não devem ser feitas somente para passar o tempo, pois a expressão corporal estimula o cognitivo e auxiliam no desenvolvimento da personalidade das crianças. De acordo com Kunz (2015, p.14),

Todo ser humano tem uma inerente necessidade de "Se-movimentar". A criança sabe muito bem disto e busca incessantemente atender a esta necessidade básica e que realiza de melhor forma o brincar. O brincar pode ser o ato mais espontâneo, livre e criativo e por isso possibilita um momento privilegiado para o desenvolvimento integral de seu ser.

Considerando a fala do autor, percebemos a importância de oportunizar o brincar livre para as crianças, uma vez que esse é um direito que deve ser garantido e possibilitado aos pequenos. Para a Professora 07 na concepção de movimento está implícito comunicação: "O movimento é uma forma de comunicação na Educação Infantil e ajuda a desenvolver a criança como um todo". O corpo se comunica como forma de expressão que não pode ser camuflada (a expressão de prazer é prazer; 
se é medo o corpo paralisa); bem diferente da linguagem verbal estruturada onde o sim as vezes é não e vice-versa. O professor tem que ficar atento a linguagem corporal das crianças para identificar se a atividade está interessante, se as crianças estão gostando ou se estão incomodadas. A respeito de comunicação e movimento, Baecker, (1996), escreve como sendo: "[...] uma condição para a interação social, porque através dela é possível ocorrer um entendimento entre os participantes da interação para a conjugação/coordenação/sincronização de suas ações". Deste modo percebemos que quanto maior as possibilidades de movimentos, maior a interação das crianças com o ambiente, objetos e pessoas.

\section{b) 0 movimento e a aprendizagem}

Em contrapartida, com uma Educação para autonomia em que o movimento da criança é privilegiado, temos o paradigma da disciplina em sala de aula que está vinculada ao silêncio e corpos disciplinados.

Na terceira parte da obra Vigiar e Punir, Michel Foucault discute sobre a questão da disciplina como forma de controlar indivíduos segundo o jogo social dominante. O controle sobre os corpos ocorre, segundo Foucault, nos detalhes, nas minúcias e, quando é controlado um corpo passa a ser um "corpo dócil" que ele define como "[...] um corpo que pode ser submetido, que pode ser utilizado, que pode ser transformado e aperfeiçoado." (FOUCAULT, 1987, p. 202).

Quando estudamos discutimos sobre corpo e movimento nessa pesquisa, isso nos levou a questionar a prática pedagógica tradicional que insiste em manter o controle sobre os corpos das crianças. As professoras foram questionadas a respeito de práticas escolares que geram a passividade das ações e corpos "dóceis".

Sobre o controle dos movimentos dos corpos das crianças, a Professora 06 afirmou que "Nem 0 adulto consegue ficar sentado o tempo todo, imagina as crianças". Na fala desta professora observamos uma crítica importante de que é inútil exigir das crianças um comportamento que os adultos também têm dificuldade de realizar e que corpos parados são entendidos como corpos em controle, aptos a aprender, no entanto, também se gasta energia nessa ação de permanecer sentados, gera cansaço. $\mathrm{E}$, ao contrário do que se pensa, o resultado desse esforço de manter-se imóvel pode vir a ser obstáculo à aprendizagem das crianças, mesmo assim, essa prática, de controle dos corpos das crianças, ainda ocorre em muitas escolas, como a autora denuncia:

O corpo da criança, logo que chega à escola, é tolhido de seus movimentos. O cognitivo é tomado como a base do objetivo do que é desenvolvido na escola e o movimento é visto, em alguns casos, como obstáculo ao desenvolvimento desse objetivo, ou ainda, como se o movimento do corpo prejudicasse o processo de aprendizagem (RICHTER, 2006, p. 36, grifos nossos).

De acordo com Foucault (1987), é por meio de normas e regras pré-estabelecidas que, internalizadas socialmente, as instituições exercem seu poder sobre o corpo do outro. A finalidade da disciplina não é outro senão a de fabricar corpos submissos, dóceis, a partir de um processo de alto disciplinamento em que os comportamentos das crianças são construídos e moldados com o passar do tempo. Diante das falas das professoras é possível fazer de outra forma, pois os enunciados delas contradizem o discurso de controle e favorecem uma educação voltada para a autonomia da criança na educação infantil.

"Se a criança não se movimentar de várias maneiras, não utilizará seu corpo para se expressar e interagir com os outros" (Professora 07). Ou seja, haverá um bloqueio de certas habilidades que 
seriam desenvolvidas por meio do corpo em movimento. Nessa perspectiva o RCNEI (1998, p. 19, grifos nossos), aponta que:

[...] um grupo disciplinado não é aquele em que todos se mantêm quietos e calados, mas sim um grupo em que os vários elementos se encontram envolvidos e mobilizados pelas atividades propostas. Os deslocamentos, as conversas e as brincadeiras resultantes desse envolvimento não podem ser entendidos como dispersão ou desordem, e sim como uma manifestação natural das crianças.

A sala de aula da Educação Infantil é um espaço repleto de trocas de experiências e para que haja aprendizagem não é preciso estar em silêncio ou quieto, posicionamento que a professora 01 concorda, ela afirma que "se a criança fica o tempo quieta, tem algo de errado, as crianças precisam de autonomia para interagir com o ambiente, se não cresce tímida e insegura." O trabalho pedagógico precisa respeitar a forma das crianças se expressarem e por isso, o professor da Educação Infantil que planeja suas aulas a partir das manifestações das crianças, observando os movimentos, as brincadeiras, as conversas delas, terá maior êxito em seu trabalho do que aquele que interpreta as manifestações infantis como falta de disciplina.

Segundo Mello (2001), se um professor limita o comportamento de uma criança no espaço por meio de uma relação de poder, ele acaba impedindo que a sala de aula seja um lugar de aprendizagem, isso fica evidente na fala da professora 05, que afirmou "Quando privamos uma criança de se movimentar, não levamos em consideração sua singularidade, nem respeitamos essa fase de descobertas da criança"e a professora 07 complementa "acho estranho e triste impedir que as crianças se movimentem, crianças que ficam apenas sentadas dentro da sala de aula parecem robôs (sem vida), criança é energia e movimento".

A partir dos relatos das professoras percebemos que não há uma visão de controle dos corpos para que haja aprendizagem, pois, segundo as professoras, as crianças estão constantemente aprendendo e desenvolvendo suas habilidades, elas atuam como mediadoras, propondo atividades desafiadoras para estimular a exploração do corpo em movimento. "Não possibilitar atividades de movimento para as crianças é uma forma de repressão, as crianças se sentem coagidas, não aprendem a se expressar e acabam se tornando tímidas e inseguras" (Professora 01)

\section{c) O espaço físico e o seu uso}

O Centro Municipal de Educação Infantil em que a pesquisa foi realizada possui sete salas de aulas, pátio coberto, parque de areia, gramado, parquinho com brinquedos e uma casinha com brinquedos diversos; as salas de aulas são organizadas de modo a valorizar a autonomia e a circulação das crianças dentro do espaço.

As professoras relataram de forma unânime a utilização de espaços ambientados de forma a possibilitar a ludicidade, brincadeiras de faz de conta e atividades de movimento corporal das crianças. Cada sala de aula possui pecinhas de encaixe, blocos de madeiras e espaços que foram construídos juntamente com as crianças. Percebemos, ainda, a partir das observações realizadas, que existem poucas mesas e cadeiras nas salas de aula, o que possibilita uma maior circulação das crianças.

Questionadas a respeito da utilização do espaço interno e externo da escola, as professoras relataram que os dois espaços são úteis para a realização das atividades, porém, o espaço externo oferece maiores possibilidades de expressão espontânea e livre das crianças. 
No que se refere ao uso dos espaços físicos da escola, a Professora 01 afirmou que "Em sala de aula trabalho com espaços ambientados, as crianças circulam livremente, quando estão muito agitadas levo elas para o gramado e faço atividades de movimento para explorar a energia delas", fala esta que é confirmada por Freire (2006, p. 16), ao afirmar que "a infância é um período muito intenso de atividades: as fantasias e os movimentos corporais ocupam quase todo o tempo da criança" e podemos inferir que desta forma ela vai aprendendo e se desenvolvendo.

A professora 01 destacou que prefere atividades de movimento no espaço externo, uma vez que a sala de aula possui um espaço limitado para algumas atividades, já a professora 02 disse que dentro da sala de aula ela tem um controle maior das crianças e o risco de se machucar é menor, porém, ela oportuniza a exploração espontânea e realiza atividades livres e dirigidas no espaço externo. Destacamos nesse momento, a importância de as crianças terem contato com atividades livres "como oportunidades para as crianças construírem e experienciarem processos de ensinar e de aprender." (NICOLIELO; SOMMERHALDER; ALVES, 2017, p. 294). O brincar de forma espontânea possibilita às crianças experimentarem a manifestação de suas ideias, interesses e a tomarem decisões. Dito de outra forma,

[...] proporciona de forma ampliada oportunidades para a criança escolher do quê, com quem e como brincar, fantasiar, dar e emitir significado as vivências da realidade, entender as diversidades da vida real possibilitando, enfim, aprendizagens para a vida. (NICOLIELO; SOMMERHALDER; ALVES, 2017, p.286).

Dessa forma, o brincar livre parte de olhar para essas atividades como experiência de cultura e formação para a vida das crianças e por isso é preciso que os professores na Educação Infantil deem maior destaque para as brincadeiras em sua prática docente, estas que são criadas e organizadas pelas crianças e carregam suas experiências de vida, de humanização e de sua cultura. (NICOLIELO; SOMMERHALDER; ALVES, 2017, p. 287).

Em relação à rotina e planejamento das atividades, as professoras relataram que a escola possui um cronograma de espaços e horários para atividades motoras. Segundo elas, nestes espaços as crianças podem brincar de forma espontânea ou as professoras realizam a mediação de uma atividade com os materiais de movimento que a escola possui tais como: bolas, bambolês, cordas, cones e brinquedos diversos.

Esclarecemos, contudo, que apesar da organização do cronograma dos espaços pela supervisora, as professoras tinham autonomia para realizar as atividades com as crianças, podendo optar por atividades semidirigidas ou livres, sem a necessidade de repetição de uma mesma atividade todos os dias.

Por meio da observação nos espaços externos percebemos que grande parte das atividades eram semidirigidas e realizadas com o grande grupo na expectativa que todas as crianças realizassem da mesma forma, no espaço do parque de areia as atividades as crianças brincavam livremente com os materiais disponibilizado pelas professoras: baldinho, pá, brinquedos e escorregador.

A postura das professoras variava entre uma abordagem somente de observação das brincadeiras e cuidado para que as crianças não se machucassem ou diretiva que dizia as crianças como e quando realizar as atividades. Desta forma percebemos que o discurso de algumas professoras não condizia com a prática. 


\section{CONSIDERAÇÕES FINAIS}

Percebe-se na fala das professoras uma preocupação em possibilitar às crianças um ensino de qualidade. Quanto à instituição pesquisada, observou-se que ela possui uma estrutura que propicia as crianças um meio favorável de desenvolvimento infantil, bem como a integração dos diversos campos de experiência.

A partir das observações podemos afirmar que na estruturação dos espaços e mediação das atividades, o corpo em movimento é valorizado pelos profissionais da escola pesquisada porque as crianças possuem autonomia para experimentar, explorar e realizar descobertas por meio de seus corpos.

Consideramos que a criança deve ser capaz de utilizar atividades de movimento em contextos que sejam significativos para suas experienciais. Trabalhar com o corpo e movimento, sem o controle dos corpos, é contribuir com as questões atitudinais das crianças, com o desenvolvimento das habilidades delas em se relacionar com o outro, tornando-as capazes de resolverem seus problemas, o que sempre ocorre em situações de jogos e brincadeiras.

A aplicação do questionário permitiu-nos perceber que as professoras possuem clareza quanto à importância da valorização do movimento e contemplam esse campo de experiência no planejamento das aulas, o que possibilita às crianças atividades desafiadoras, porém ainda há um distanciamento da fala versus prática.

Inferimos que o movimento não deve ser visto como algo relacionado ao aspecto físico ou como forma de lazer. O mesmo deve estar relacionado aos aspectos emocionais, cognitivos e sociais, uma vez que a criança se desenvolve e aprende de todas as formas e, por isso, ato de educar não deve ser realizado de forma fragmentada, mas precisa considerar a criança em sua totalidade. O professor é um mediador entre a criança e os objetos, uma vez que as crianças precisam de estímulos, desta forma o movimento na Educação Infantil deve ser trabalhado para que a criança seja capaz de desenvolver suas emoções de forma completa, enfrentando suas dificuldades e ir além de suas próprias expectativas.

A escola pesquisada possui um espaço amplo para circulação e interação das crianças e as professoras percebem a necessidade de um trabalho que contemple o movimento das crianças e estão cientes que o corpo está associado a mente e que a criança aprende com o corpo inteiro e que o movimento não serve somente para executar o que a criança pensa, mas, também, é a forma pela qual ela aprende.

Acreditamos que essa pesquisa pode colaborar para a conscientização dos profissionais da educação no que se refere à relevância de contemplar o movimento no planejamento diário, bem como possibilitará uma reflexão sobre o erro em separar corpo e mente, uma vez que a aprendizagem ocorre com o corpo em movimento.

Destacamos que comportamento infantil ao passar por diversas punições como forma de correção passa a ser passivo e essa passividade, naturalizada dentro da nossa sociedade, precisa ser combatida no campo educacional. Faz-se necessário questionar, problematizar e construir novas práticas e discutir sobre essa questão de controle dos corpos como forma de desenraizar tais práticas tão arraigadas nas escolas. Como formar cidadãos críticos se não iniciarmos ainda na Educação Infantil? Somente dessa forma, a partir desse posicionamento demonstrado através de novas práticas na 
Educação Infantil é que a Escola será capaz de contribuir para a formação de sujeitos mais críticos, capazes de refletir e discutir sobre a realidade que o cerca.

A partir dessa pesquisa e diante das discussões aqui propostas, podemos perceber que a sala de aula da Educação Infantil precisa ser dinâmica e, portanto, estar em frequente movimento. Cabe aos professores dessa etapa de ensino refletirem a respeito de sua prática docente a fim de atender às crianças de forma significativa, considerando suas vivências e a necessidade dos corpos das crianças.

\section{REFERÊNCIAS}

ARRIBAS, Teresa Lleixà. Educação Infantil: desenvolvimento, currículo e organização escolar. 5. ed. Porto Alegre: Artmed, 2004.

BAECKER, Ingrid Marianne. Promovendo Identidade em Movimento Ensinar a escola primária brasileira. Tese. (Dissertação) -Universidade de Hamburgo, República Federal da Alemanha:1996.

BARDIN, Laurence. Análise de Conteúdo. Lisboa: Edições 70, 1977.

BRASIL. Secretaria de Educação Fundamental. Referencial curricular nacional para a Educação Infantil. Brasília: MEC/SEF, 1998.

BRASIL. Secretaria de Educação Fundamental. Parâmetros Curriculares Nacionais (PCN's). Brasília: MEC/SEF, 1997.

BRASIL. Câmara de Educação Básica. Resolução no 5, de 17 de dezembro de 2009. Diretrizes Curriculares Nacionais para a Educação Infantil. Brasília: MEC, 2009.

BRASIL. Secretaria da Educação Básica. Base Nacional Comum Curricular. Brasília: MEC, 2017.

CHATEAU, Jean. O Jogo e a Criança. São Paulo: Summus, 1987.

CLARA, Cristiane; FINCK, Silvia. A educação psicomotora e a prática pedagógica dos professores da educação infantil: interlocuções e discussões necessárias. IX ANPED SUL. Seminário de pesquisa em Educação da Região Sul: UEPG, 2012.

FIORENTIN, Sabrina. Corpo e corporeidade nas percepções e as práticas pedagógicas de professores da educação infantil especial: da visão mecanicista / reducionista à visão sistêmica / holística. Dissertação (Mestrado) - UTP, Universidade de Tuiuti do Paraná, Curitiba: 2006.

FOUCAULT, Michel. Vigiar e punir: história das violências nas prisões. Rio de Janeiro: Vozes, 1987.

FREIRE, João. Batista. Educação de corpo inteiro: teoria e prática da Educação Física. São Paulo: Scipione, 2006.

GARANHANI, Marynelma Camargo. A Educação física na Educação infantil: uma proposta em construção. In: FILHO, Nelson F. A.; SHNEIDER, Omar (Org.). Educação Física para a Educação Infantil conhecimentos e especificidades. Aracaju: Editora UFSE, 2008.

GIL, Antônio. Carlos. Métodos e técnicas de pesquisa social. 5. ed. São Paulo: Atlas, 1999. 
GONSALVES, Elisa Pereira. Conversas sobre iniciação à pesquisa científica. São Paulo: Alínea, 2001.

KUNZ, Elenor. (org.). Brincar e se-movimentar: tempos e espaços de vida da criança. Ijuí: Ed. Unijuí, 2015.

LUDKE, Menga; ANDRÉ, Marli. Pesquisa em educação: abordagens qualitativas. São Paulo EPU, 1986.

MELLO, Maria Aparecida. A atividade mediadora nos processos colaborativos de educação continuada de professores: educação infantil e educação física. Tese (Doutorado) -Universidade Federal de São Carlos, São Paulo: 2001.

MIRANDA, Made Junior. Estudo dos aspectos ambientais, socioeconômicos e do desempenho motor de crianças residentes nas proximidades do Ribeirão Anicuns, Goiânia - GO. Dissertação (Mestrado em Ciências Ambientais e Saúde) -Universidade Católica de Goiás, Goiânia: 2008.

RICHTER, Leonice Matilde. Movimento corporal da criança na educação infantil: expressão, comunicação e interação. Dissertação (Mestrado) -UFU, Universidade Federal de Uberlândia, Minas Gerais: 2006.

NICOLIELO, Maria Elisa; SOMMERHALDER; Aline; ALVES, Fernando Donizete. Brincar na educação infantil como experiência de cultura e formação para a vida. Revista Educação. Rio Grande do Sul, v. 42, n. 2, p. 285-298, maio/ago. 2017. Disponível em:

https://periodicos.ufsm.br/reveducacao/article/view/22271. Acesso em: 12 jun. 2021

SILVA. William Vagner da. O movimento corporal na educação infantil: em busca da compreensão do cotidiano da sala de aula. Dissertação de Mestrado em Educação. Universidade Federal de São João Del Rei - UFSJ, São João Del Rei: 2011.

Submissão: 14/04/2021

Aceito: 22/06/2021 